\title{
Carbon Monoxide in Gas.
}

\section{By Prof. John W. Coвb.}

THE following paragraph appeared in The Times for February II, under the heading "Carbon Monoxide Peril."

"The Board of Trade has drafted a special Order under the Gas Regulation Act, I920, relating to carbon monoxide in gas used for domestic purposes. The Order provides that: No gas undertakers as defined by the Gas Regulation Act, I920, shall supply any gas for domestic purposes containing carbon monoxide unless such gas possesses the distinctive pungent smell of coal gas. The Order requires the approval of both Houses of Parliament."

The announcement needs some explanation, as probably nobody in this country has ever come across a public gas supply without a very distinctive and pungent smell.

When Sir George Beilby and the Fuel Research Board were called upon by the Board of Trade, some time ago, to make recommendations for the future regulation of public gas supply, they recognised in effect that radical improvements and economies by the gas manufacturers could be secured by the gasification of the fixed carbon of the coal by some such process as that of the steaming of vertical gas retorts or the gasification of coke in external generators with steam-the so-called water-gas process.

The increase in the carbon monoxide content of the gas so involved depended upon the extent to which the fixed carbon was gasified. The recommendations then made form the basis of the Gas Regulation Act of I920, but when the Act was passed it was decided that the Board of Trade should institute inquiries on two special points, one of which was " whether it is necessary or desirable to prescribe any limitations of the proportion of carbon monoxide which may be supplied for the gas used for domestic purposes." The inquiry was made and evidence taken by a Committee from witnesses who regarded this matter from different points of view, and set out their arguments at length. It became plain that the economic advantages offe, ed by the new Act depended very largely on freedom to supply gas containing more carbon monoxide, and that even on the side of hygiene the position was not so simple as might appear at first sight. Any danger from carbon monoxide had to be placed against the improvement of public health which would result from the progressive abolition of smoke as gas replaced raw coal for heating purposes, and it had to be realised that in no circumstances would it be practicable to supply gas containing little or no carbon monoxide, since ordinary " straight" coal-gas might contain ro per cent or more.

It is not surprising, therefore, that the Committee recommended against statutory limitation of carbon monoxide in public gas supply. It was, however, possible that the conditions of manufacture might at some time or place be changed to such an extent that the gas then supplied to the public would be nearly odourless unless some means were taken to confer a smell upon it, and to meet that possibility of the future it was recommended that the distribution of an odourless gas should be made an offence.

The Board of Trade Order, which has just been drafted, will carry that recommendation into effect. It is no doubt hoped that it will also have on the public mind the beneficial effect of a psychological antitoxin, which seems to be needed at the present time.

During the last two months of severe weather, the number of accidents from gas poisoning undoubtedly increased. Various factors have been operative in bringing this about, including the tendency to restrict ventilation owing to the cold, and to use gas heating appliances of all kinds, in all sorts of places, and particularly in bedrooms. Public attention, however, having been directed to the fact that carbon monoxide in public gas supply might increase considerably in the future owing to the Gas Regulation Act, people have arrived at the mistaken conclusion that such increase had already taken place and was solely responsible for these accidents. It would, as a matter of fact, greatly surprise the present writer to learn that the carbon monoxide content of gas responsible for any one of these accidents was above the permissible limit recommended by the advocates of restriction before the special Committee to which reference has been made above. In the gas supply of Ieeds, which has come under the writer's own tests, the percentage of carbon monoxide has been actually considerably lower than it was during the summer months of the coal strike, and no higher than in the preceding winter. Nor is there any reason to suppose that the condition so described is exceptional.

\section{The Brain of Rhodesian Man.}

$\mathrm{A}^{\mathrm{T}}$ a meeting of the Royal Anthropological Rivers, preside held on February I4, Dr. W. H. R. described the brain of Rhodesian man.

The excellent endocranial cast which Mr. Frank Barlow, of the Natural History Museum, has been able to obtain from the Rhodesian skull is of exceptional importance. In the first place, it affords evidence which settles once for all the position of Homo rhodesiensis in the human family and its varying degrees of affinity to the different members of the family ; and, secondly, it provides very precise information concerning the size, shape, and stage of development of the brain of Rhodesian man, so that when the endocranial casts of Pithecanthropus, Eoanthropus, and Homo Neanderthalensis are compared with it and the whole series is considered in the light of the new information, a fuller understanding of the process of evolution of the human brain is attained. Moreover, the endocranial cast enables us definitely to settle the dispute as to the posture of Rhodesian man, or at any rate as to how he carried his head.

Prof. John Hunter, of the University of Sydney, has made a series of exact orthogonal projections of the endocranial casts of the extinct types of the human family and of the anthropoid apes, and has shown that Rhodesian man's head was thrust forward on his tremendously massive neck at an angle almost exactly intermediate between that of the gorilla and modern man-a degree of obliquity almost identical with that of Gibraltar man and probably a little more than that of the man of La Chapelle-auxSaints. The peculiarly distinctive features of the base of the skull of Rhodesian man corroborate this interpretation. The cranial capacity is 1280 c.c., which is roughly equal to that of the Gibraltar skull, but much smaller than all the other members of the

$$
\text { NO. 2733, VOL. IO9] }
$$


Neanderthal species. It is definitely bigger than the Piltdown cast.

Like the endocranial casts of Pithecanthropus and Eoanthropus, that of the newly discovered skull reveals a marked deficiency in the prefrontal and inferior temporal areas. But as in all these primitive members of the human family, there is an obtrusive prominence in the auditory territory which suggests that the cultivation of the acoustic symbolism necessary for the acquisition of articulate speech was a very important, if not the dominant, factor in the attainment of the human status. This localised expansion in the superior temporal area is responsible for the peculiar form of all primitive human brains, i.e. their relatively great width and flatness. The expansion of the cortex has been carried a stage further than in the Piltdown brain and has led to a fuller development of the inferior parietal territory, but the superior parietal area is still ill-developed - and flat.

Thus the Rhodesian cast reveals a stage definitely more primitive than that of Neanderthal man and helps us to understand the features of the latter. The significance of the peculiarities, so far as they shed light upon the evolution of the human brain, was discussed, and the speaker expressed his gratitude to Dr. Smith Woodward of the British Museum for affording him the opportunity for studying the Rhodesian skull and the endocranial cast obtained from it.
The president, in opening the discussion, said that he had been particularly struck by the demonstration of the development of those parts of the brain that are connected with mind, and it was interesting to note that those parts which were latest in development of the child were those in which Rhodesian man stood intermediate between the gorilla and modern man.

Dr. Smith Woodward regretted the absence of geological or palæontological data which might throw light upon the age of the skull. Any attempt to determine its age must depend upon the character of the skull itself. Prof. Elliot Smith had made a beginning of the scientific study of this evidence, and it should be possible to determine its position in the human series apart from geological evidence. Prof. W. Wright said that Prof. Elliot Smith had given a clear demonstration of the development of the brain from the lowest primates to Dean Swift. Would it not be possible to go a little further and prophesy that the future development of the brain would be in the direction of filling those parts of the cranial cavity which were at present ill-filled? $\mathrm{He}$ agreed that the author was justified in now placing Pithecanthropus definitely within the human family. Prof. Parsons said that the present communication indicated the value of the endocranial cast in ethnological investigation, and that this method of study should be applied to the investigation of the problems connected with modern races.

\section{Evolutionary Faith and Modern Doubts.}

$\mathrm{IN}$ a notable address on the above subject at the Toronto meeting of the American Association for the Advancement of Science, which is printed in Science for January 20, Dr. William Bateson discusses particularly the changes in point of view which have followed each other since the Darwinian period and the end of last century. The morphological school worked itself out, and was followed by the development of genetic experiments. It was seen that the gradual transformation of species over large areas was an unacceptable doctrine. From field studies of pairs of species it was concluded that both could not have come from an intermediate ancestor through gradual divergence by natural selection, nor could either have given rise to the other by such a process.

Then Mendelism seemed to furnish an explanation of the discontinuity of species--a discontinuity which had long been denied by those evolutionary philosophers who were not systematists. Nevertheless, the result has been disappointing, and the attempt to explain evolution in Mendelian terms has finally been dropped. This is because evolutionary conceptions have dealt with zygotes, or the bodies of plants and animals as we see them, while genetic research has revealed the interactions of an inner world of gametes upon which the zygotes depend for their origin. Dr. Bateson further records his full conversion to the belief that the chromosomes are directly associated with the characters of the zygote. "The transferable characters borne by the gametes have been successfully referred to the visible details of nuclear configuration."

Although we see variations in abundance on all hands, the origin of species is still obscure, and genetic analysis has not enabled us to account for certain phenomena, especially the origin of new dominant characters and of sterility. The question of species-origin is believed to be concerned with the base upon which transferable characters are implanted, but of this base we at present know nothing. Dr. Bateson concludes a remarkable survey with an appeal for closer co-operation between geneticists and systematists, and finally points out that the fact of evolution is not in doubt, although the manner of the origin of species remains a mystery.

R. R. G.

\section{The Teeth of the Nation. ${ }^{1}$}

THE lecturer began by directing attention to a series of skulls exhibited, kindly lent for the occasion by Sir Arthur Keith. Skulls of Neolithic date showed perfect dentition, though the teeth were worn a good deal by attrition ; the skulls of to-day exemplified the ravages of dental caries, or of the equally prevalent disease of gums and jaws called pyorrhœa. One modern skull with a perfect set of teeth was the rarest specimen he could show. Caries was not unknown in past ages, and even the teeth in the Rhodesian skull exhibit it. The seriousness of ', 1 Abstract of a discourse delivered at the Royal Institution in February ro by Prof. W. D. Halliburton, F.R.S. the increase in dental decay in recent times is such that the Ministry of Health has appointed a special Committee to investigate its causes and prevention. Cleanliness is a necessary duty, and the tooth-brush, unless supplemented by antiseptic mouth-washes, is an imperfect instrument. The danger is the accumulation of food-débris in chinks and crevices and the formation of acids such as lactic acid by bacteria, especially if the food is soft and sticky and contains easily fermentable sugars of the glucose type: Such acid has a solvent action on the protective layer of enamel, and in time on the dentine which it covers.

The teeth, however, are not mere ornaments to be

NO. 2733 , VOL. IOg] 